\title{
Increase of uterine motility and simultaneous decrease of progesterone concentrations in the rat after bilateral ovariectomy at mid-pregnancy
}

\author{
M. Clabaut, R. Duclos and S. Acritopoulou-Fourcroy \\ Laboratory of Foeto-Maternal Physiopathology, Faculty of Sciences, University of Rouen, \\ Mont-Saint-Aignan 76130, France
}

\begin{abstract}
Summary. Comparison of uterine activities recorded during the control period to those obtained during the two recording periods after ovariectomy $(0-30 \mathrm{~min}$ and $30-60 \mathrm{~min})$ showed an increase of the amplitude of uterine contractions $(P<0.005)$ and a decrease of the interval between two successive uterine contractions $(P<0.005)$ and the delay of electrical activities $(P<0.005)$. Progesterone treatment $(50 \mathrm{mg} / \mathrm{kg}$ i.m. $)$ of ovariectomized rats prevented the abrupt fall in plasma progesterone concentrations, measured by RIA, which in turn inhibited the increase of uterine mechanical and electrical activities. A close relation between the increase of myometrial activity and the decrease of progesterone concentrations after ovariectomy is suggested. The activation of the myometrium would be principally induced by the fall of progesterone or by the variation of the oestrogen/progesterone ratio; these changes in sexual steroid hormones would augment the uterine sensitivity to physiological stimuli or modify the activity of other factors involved in the regulation of the myometrium.
\end{abstract}

Keywords: uterine motility; mid-pregnancy; ovariectomy; rat

\section{Introduction}

In the rat, removal of ovaries before Day 14 of pregnancy induces embryonic death and resorption within $48 \mathrm{~h}$ (Madjerek et al., 1960; Csapo \& Wiest, 1969). Histological study shows that ovariectomy on Day 7 or 8 of pregnancy results in a collapse of the decidua and embryonic death $12 \mathrm{~h}$ later; on Day 10 or 11 of gestation embryonic death appears $24-36 \mathrm{~h}$ later and is associated with intense vascular feto-maternal perturbations (Clabaut, 1969, 1972, 1973; Deanesly, 1973; Peel \& Bulmer, 1974). Myometrial and embryonic shrinkage is often observed after ovariectomy (Clabaut, 1972). Embryonic death is closely related to the fall in peripheral progesterone concentrations (Butterstein \& Hirst, 1977; Clabaut, 1977); the relation between abortion and the progesterone fall is confirmed by the abortive effects of progesterone synthesis inhibitors in the rat at mid-pregnancy, e.g. azastene (Creange et al., 1978) or isoxazole (Csapo et al., 1979; Carnathan et al., 1981). However, pregnancy can be maintained if a progesterone injection is given concurrently with azastene (Creange et al., 1978). Administration of progesterone antiserum (Csapo et al., 1975) causes an immediate fall in progesterone concentrations and induces termination of gestation. Similarly, Csapo \& Resch (1979) reported that progesterone antiserum provokes an increase of uterine motility and preterm labour. In late pregnant sheep, trilostane (another progesterone synthesis inhibitor, $100 \mathrm{mg}$ ) induces a rapid progesterone withdrawal and delivery (Taylor et al., 1982). In the human excision of the corpus luteum in early pregnancy induces activation of the myometrium that is proportional to the decrease of progesterone concentrations (Csapo \& Pulkkinen, 1978). 
The objective of the present investigation was therefore to examine whether bilateral ovariectomy during mid-pregnancy in the rat would engender activation of uterine motility and consequently accelerate embryonic death.

\section{Materials and Methods}

Animals. Adult Wistar rats, on Day 8-11 of pregnancy, weighing $200-250 \mathrm{~g}$, were used. Animals were kept under a lighting schedule of $12 \mathrm{~h}$ light $/ 12 \mathrm{~h}$ dark at $23^{\circ} \mathrm{C}$ with free access to food (U.A.R. No. 103, Villemoisson sur Orge, France) and water. Female and male rats were caged together overnight and the next morning vaginal smears were examined for the presence of spermatozoa. This day was designated as Day 1 of pregnancy. Animals were randomly allocated to four groups. In Group 1, rats were sham-operated, in that two ligatures were placed near each ovary. In Group 2, rats were ovariectomized but not treated. In Group 3, rats were sham-operated and ovariectomized but received $3 \mathrm{i} . \mathrm{m}$. injections of vehicle. In Group 4, rats were ovariectomized and treated with progesterone.

Surgery and measurement of uterine contractions. After anaesthesia with pentobarbitone sodium (Nembutal: Abbott, St Remy sur Avre, France; $40 \mathrm{mg} / \mathrm{kg}$ i.p.) the trachea was cannulated. The abdomen was then opened by a midline incision and two ligatures, one around the vascular pedicle and the other over the fimbria, were placed on each ovary of the rats to be ovariectomized. Thereafter, the rat was placed supine on a heated operating-table at $37^{\circ} \mathrm{C}$ and was prepared for in-situ recordings of uterine contractions as follows. The ovarian end of one uterine horn was linked with an isometric strain gauge by means of a cotton tension thread passed near the oviduct; the uterine horn was tied firmly with a second cotton tension thread passed towards the cervix to a metal rod fixed vertically on the back part of the operating-table for maintaining strict isometric conditions. The tension applied to the uterine horn at the beginning of the experiment was $1 \mathrm{~g}$. While manipulating the reproductive tract great care was taken to limit the stretching of the uterine muscle to a minimum. The gauge was connected to a transducer coupled to an ink-recording polygraph (E.C.E.M., Ozoir-la-Ferrière, France). Throughout the experiment Tyrode solution at $37^{\circ} \mathrm{C}$ was dripped down the outside of the uterine horn to keep it moist. This device records isometric contractions primarily of the longitudinal myometrial layer. Spontaneous electrical activity of the myometrium was recorded simultaneously by two bipolar concentric stainless-steel recording electrodes of a $50 \mu \mathrm{m}$ outer diameter, placed on the outside of the uterine horn $1 \mathrm{~cm}$ from each other. These three simultaneous recordings allow evaluation of whether mechanical activity is propagated throughout the uterine horn and whether the electrical activities are asynchronous or synchronous.

After stabilization of the system for about $30 \mathrm{~min}$ spontaneous uterine contractions and electromyograms were recorded simultaneously for a further $30 \mathrm{~min}$ before surgery. This first recording period is designated as control recording. Recording was then continued for a further $1 \mathrm{~h}$.

Progesterone administration. In Group 4 rats, after the control recording and just before ablation of the ovaries, progesterone $(50 \mathrm{mg} / \mathrm{kg})$ in $0.5 \mathrm{ml}$ vehicle (oily solution; Lafaye \& Frigot, 1978) was given by 3 successive i.m. injections given at 3 different places on the thigh. In Group 3, after the control recording and just before ovarian ablation, $0.5 \mathrm{ml}$ vehicle was given by 3 successive i.m. injections given equally at 3 different places on the thigh.

Measurement of the uterine contractions and myometrial electrical activity. Variations in myometrial mechanical activity were evaluated in terms of amplitude, frequency, and interval between two successive contractions. Amplitude corresponds to the maximal amplitude of each uterine contraction. Frequency was determined by counting the total number of contractions developed within $30 \mathrm{~min}$ and the interval between two successive contractions of the uterus was recorded. The value of $100 \%$ is arbitrarily attributed only to the control mean amplitude.

After the control recording contractility was further recorded continuously for up to $30 \mathrm{~min}$ and then between 30 and $60 \mathrm{~min}$. The control means for amplitude, frequency and interval were compared to the equivalent means for each of the 30-min recording intervals after ovariectomy $(0-30 \mathrm{~min}$ and $30-60 \mathrm{~min})$. To measure the activity variations of the 2 electromyograms, one characteristic, termed the delay (D), was considered to be the time interval evaluated in sec during which electrical activity was recorded only at the level of one of the two electrodes (see Fig. 1 and Table I).

Plasma progesterone concentrations. Two blood samples of $1 \mathrm{ml}$ each were withdrawn by jugular puncture, the first just before ovariectomy or sham-operation and the 2 nd one as indicated in Table 2. The first blood sample was withdrawn after transient anaesthesia with ether; thereafter animals were allowed to regain conciousness and were anaesthesized again before the 2 nd bleeding.

Concentrations of plasma progesterone were measured by RIA as described previously by Scaramuzzi $e t$ al. (1974). The antiserum used (Biomérieux, Marcy-l'Etoile, France) was raised in a rabbit against $11 \alpha$-hydroxyprogesterone-11-hemisuccinate-bovine serum albumin. This antiserum cross-reacts with desoxycorticosterone $(<6.6 \%)$, $20 \alpha$-dihydroprogesterone $(<0.5 \%)$, pregnenolone, oestradiol and corticosterone $(<0.0001 \%)$. The sensitivity of the assay was $20 \mathrm{pg} /$ tube and the mean recovery was $55 \pm 3 \%$. The interassay coefficient of variation and the coefficient of variation of duplicate pairs in this study were $<10 \%$. Accuracy of the method was determined by adding known quantities of progesterone to $0.5 \mathrm{ml}$ samples from a pool of rat plasma: additions of $0.1,0.2,0.4,1.0$ and $2.0 \mathrm{ng}$ gave measurements of $0.11 \pm 0.01,0.19 \pm 0.01,0.40 \pm 0.02,0.96 \pm 0.03$ and $2.02 \pm 0.03 \mathrm{ng}$, respectively. 
Statistical analysis of the data. Data were analysed using Wilcoxon non-parametric statistics. Student's $t$ test was used to compare the significance of differences between means with respect to Group 2 rats. Plasma progesterone concentrations were compared by a related samples test.

\section{Results}

\section{Uterine motility}

Sham-operation effects in Group 1. Sham-operation did not modify the mechanical or the electrical activity of the uterine muscle during the control recording (Table 1).

Ovariectomy effects. During the control recording myometrial mechanical activity was moderate, and the electrical activity was characterized by a long delay (see Fig. 1). However, ablation of ovaries (Group 2) provoked a significant increase in the amplitude, a decrease in the interval of the uterine contractions, without variation in the frequency, and a significant decrease of D (Table 1), consequently a significant increase in the duration of the contractions was observed. This increase in mechanical myometrial activity was associated with a rise of the slope of the contraction curve and an increase in the frequency of the EMG bursts (Fig. 1).

Sham-operation effects in Group 3. Injection of the progesterone-vehicle did not modify either the mechanical or the electrical activity of the uterine muscle observed after ablation of ovaries in Group 2 (Table 1).

Effects of ovariectomy associated with progesterone injection. Administration of progesterone immediately before ovariectomy in Group 4 maintained the mechanical activity of the myometrium at its initial level. An increase of the $\mathrm{D}$ value $(P<0.01)$ was recorded, starting during the period of 0-30 min after ovariectomy, but thereafter this value remained steady. Comparison of mean values of amplitude and interval in Groups 2 and 4 shows a significant difference as early as 30 min after ovariectomy (Table 1). The mean D values in Groups 2 and 4 were also significantly different by 30 min after ovariectomy (Table 1$)$.

\section{Plasma progesterone concentrations}

Sham-operation effects. Plasma progesterone concentrations were not altered in Group 1 rats 24 h later (Table 2).

Effects of ovariectomy. In Group 2 rats progesterone concentrations decreased $(P<0.01)$ by $30 \mathrm{~min}$ after ovariectomy and were lower by $60 \mathrm{~min}(P<0.001)$. At $24 \mathrm{~h}$ after ovariectomy progesterone values were $21 \%$ of the control values (Table 2 ).

Effects of ovariectomy and progesterone administration. Exogenous progesterone (Group 4) redressed within $30 \mathrm{~min}$ the abrupt fall in progesterone concentrations that occurred after ovariectomy. Concentrations were increased $(P<0.001)$ at $60 \mathrm{~min}$ after injection when compared both to those of Group 1 and Group 2 animals, and were still high $6 \mathrm{~h}$ later (Table 2). However, progesterone values at $24 \mathrm{~h}$ after injection were lower than those of controls $(P<0.01)$.

\section{Discussion}

We have demonstrated that ovariectomy at mid-pregnancy results in an early increase of myometrial activity concomitant with a decrease in the delay of electrical activities and the progressive establishment of a better propagation of action potentials. A significant increase of the myometrial activity occurs when progesterone concentrations are reduced by $20 \%$; this increase becomes highly significant (see Table 1, Group 2) when progesterone values are decreased by $50 \%$ compared to control values. Neither mechanical nor electrical activities of the myometrium were modified when only two ligatures were placed near each ovary (Group 1); this may mean that 


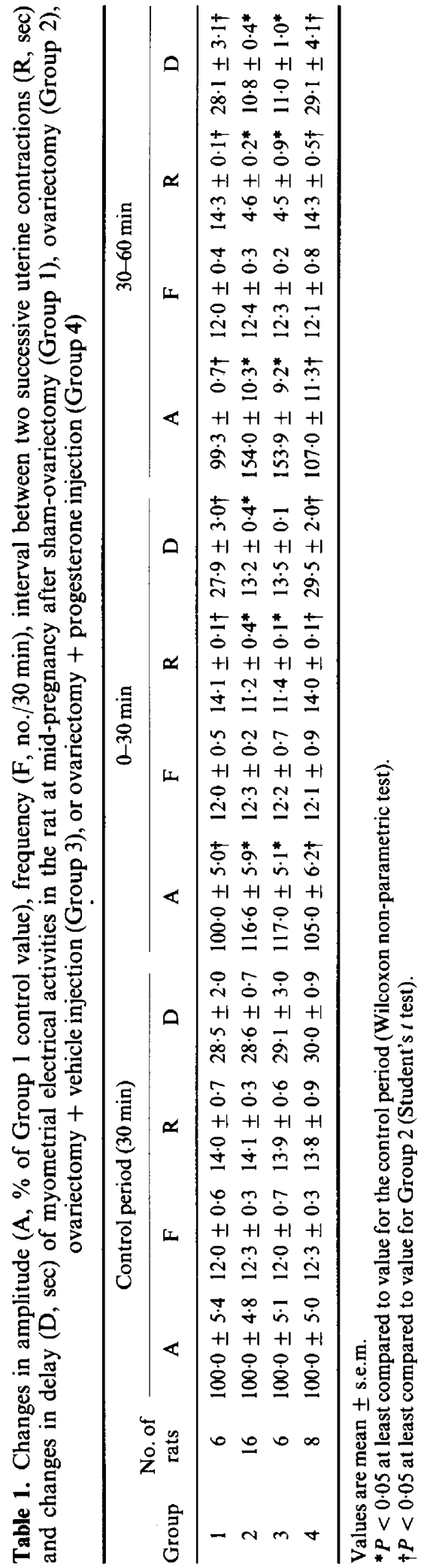


Before ovariectomy (control recording)

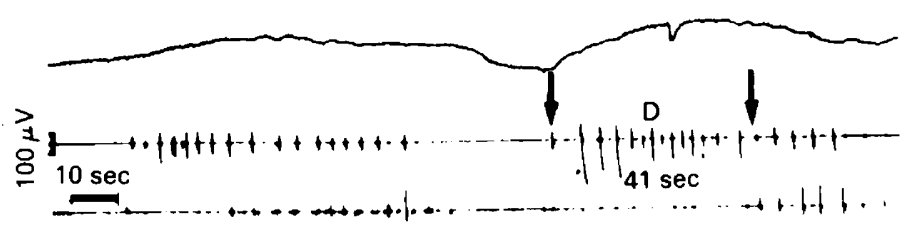

$30 \mathrm{~min}$ after ovariectomy

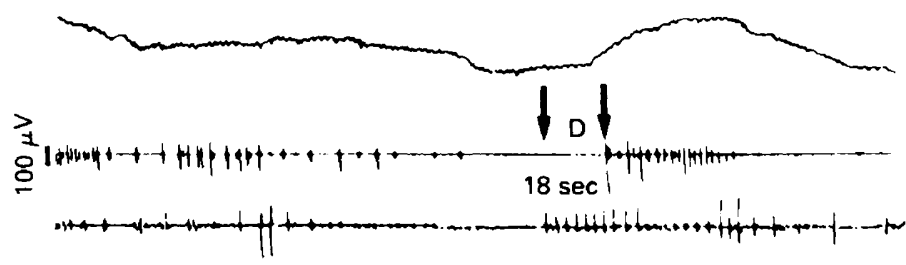

60 min after ovariectomy

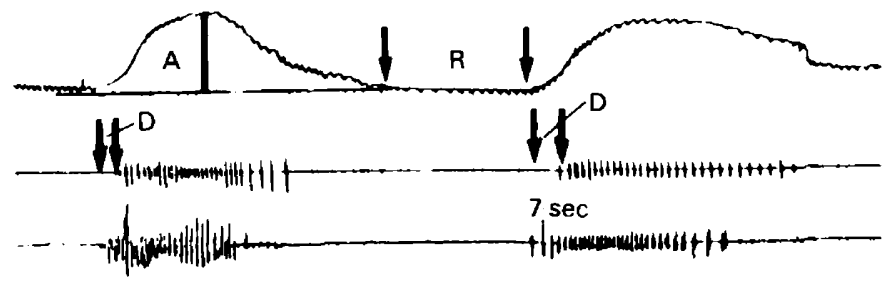

$60 \mathrm{~min}$ after ovariectomy

and progesterone administration

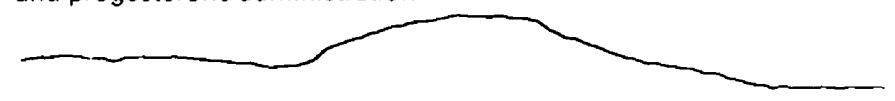

7

Fig. 1. Tracings of uterine mechanical and electrical activities in rats. $A=$ amplitude; $R=$ time interval; $\mathrm{D}=$ delay. In each panel, the top trace is myometrial mechanical activity, the middle trace is distal electrical activity and the bottom trace is proximal electrical activity.

Table 2. Plasma progesterone variations in rats in Groups 1,2 and 4 in relation to ovariectomy (ovex)

\begin{tabular}{cccccc}
\hline & \multicolumn{5}{c}{ Progesterone conc. (ng/ml) } \\
\cline { 2 - 6 } Group & $\begin{array}{c}\text { Before ovex } \\
\text { (control) }\end{array}$ & $30 \mathrm{~min}$ & $60 \mathrm{~min}$ & $6 \mathrm{~h}$ & $24 \mathrm{~h}$ \\
\cline { 3 - 6 } & $94 \cdot 3 \pm 13 \cdot 6$ & - & - & - & $90 \cdot 5 \pm 9 \cdot 5$ \\
\hline 1 & $(6)$ & & & & $(6)$ \\
& $92 \cdot 9 \pm 11 \cdot 3$ & $62 \cdot 3 \pm 13 \cdot 9 *$ & $50 \cdot 8 \pm 9 \cdot 6^{* *}$ & $41 \cdot 2 \pm 17 \cdot 5 * *$ & $21 \cdot 7 \pm 14 \cdot 9 * *$ \\
2 & $(52)$ & $(15)$ & $(15)$ & $(12)$ & $(10)$ \\
4 & $93 \cdot 1 \pm 0.8$ & $97 \cdot 1 \pm 17 \cdot 2$ & $154 \cdot 6 \pm 12 \cdot 3^{* *}$ & $157 \cdot 7 \pm 13 \cdot 2^{* *}$ & $69 \cdot 4 \pm 14 \cdot 7^{*}$ \\
& $(24)$ & $(6)$ & $(6)$ & $(6)$ & $(6)$ \\
\hline
\end{tabular}

Values are mean \pm s.e.m. for the no. of animals indicated in parentheses.

${ }^{*} P<0.01 ;{ }^{* *} P<0.001$ compared with control value (related samples test). 
increase in myometrial activity is induced by ovarian ablation. As expected, uterine activity was not increased in the ovariectomized progesterone-treated rats (Group 4). In addition, the triple i.m. injection of the vehicle only in the thigh at the time of ovariectomy (Group 3) did not alter uterine activity. These results demonstrate that it is the progesterone injection, given at the time of ovariectomy, which blocked the changes in amplitude, interval and $\mathrm{D}$ value and not the administration of the vehicle only or the mechanical effect of triple i.m. administration. The present results are in line with those of Kuriyama \& Suzuki (1976) postulating that, in the rat during mid-pregnancy, the behaviour of the myometrium is nearly the same as that induced by progesterone treatment. Progesterone induces hyperpolarization of the myometrial membrane (Marshall, 1959; Kuriyama \& Suzuki, 1976). Salvidar \& Melton (1966), working in vivo, reported that administration of progesterone does not change uterine activity in the rat. In contrast, according to Fuchs (1978) progesterone inhibits conduction of the propagated activity; this inhibition disappears during the decrease of progesterone concentrations but it does not remove the contractile activity of the myometrium in the mid-pregnant rat. The increase in propagation of electrical activity after ovariectomy would have been induced by the formation of junctions in myometrial tissues and it would mediate the decrease in the delay parameter. This hypothesis was supported by Garfield et al. (1978b) who reported that the appearance of junctions was induced prematurely by ovariectomy in pregnant rats and was prevented by progesterone. In addition, Garfield et al. (1977, 1978a, b) postulated that formation of gap junctions was stimulated in the immediate peripartum period by a fall in progesterone levels. Our plasma progesterone concentrations, measured on blood withdrawn from animals under ether anaesthesia, are comparable to those reported by others (Wiest, 1970; Morishige et al., 1973; Egg et al., 1974), although Bruce et al. (1984) reported that plasma progesterone concentrations were about $30 \%$ higher and more variable in anaesthetized animals than in conscious rats. The resting concentration of progesterone $(20 \%) 24 \mathrm{~h}$ after ovariectomy seems to be secreted by the adrenal glands because ovariectomy associated with adrenalectomy causes a drastic fall of progesterone (Butterstein \& Hirst, 1977; Clabaut et al., 1977; Bruce et al., 1984).

In addition, at mid-pregnancy ovariectomy induces simultaneously a fall of plasma progesterone concentrations and an activation of the myometrium; these phenomena precede abortion observed 12--24 h after ovariectomy. However, Talo \& Karki (1977), after ergocornine administration at mid-pregnancy, observed at first a fall of plasma progesterone concentrations followed by an activation of the myometrium and then abortion. The progesterone-dominated uterus should therefore be refractory to stimulants, and progesterone withdrawal would convert the uterus to a spontaneously reactive organ (Fuchs, 1978; Csapo \& Pulkkinen, 1978). At mid-pregnancy after ovariectomy the rapidity of initiation of electrical and mechanical activation of the myometrium oestrogens/progesterone should have a direct effect on the uterine muscle, by increasing its sensitivity to physiological stimuli such as prostaglandins (Clabaut et al., 1986). Moreover the activation of the myometrium after ovariectomy should be increased by an eventual decrease of plasma relaxin concentrations; relaxin, a strongly utero-inhibitory hormone, has been clearly detected in the ovaries in mid-pregnancy in the rat (Golos et al., 1984).

We thank Dr M. Terqui for introducing us to the techniques of RIA of steroid hormones in his Laboratory, INRA, Station de Physiologie de la Reproduction, 37380 Nouzilly; and Miss A. Dufour for typing the manuscript.

\section{References}

Bruce, N.W., Willcox, D.L., Meyer, G.T. \& Waddell, B.J. (1984) Effects of handling, anaesthesia, ovariectomy and adrenalectomy on serial measurements of plasma progesterone in 16-day pregnant rats. $J$. Endocr. 100, 189-193.
Butterstein, G.M. \& Hirst, J.A. (1977) Serum progesterone and foetal morphology following ovariectomy and adrenalectomy in the pregnant rat. Biol. Reprod. 16, 654660 .

Carnathan, G., Metcalf, L., Cohrane, R. \& Nutting, E. 
(1981) Progesterone depression and pregnancy maintenance during midgestation in rats. Biol. Reprod. 24, Suppl. 1, 141, Abstr.

Clabaut, M. (1969) Premiers signes histologiques de l'avortement après ovariectomie bilatérale chez la ratte. C. r. Séanc. Soc. Biol. 163, 21-24.

Clabaut, M. (1972) Effets de la biovariectomie sur la jonction embryo-maternelle chez la ratte gestante avant le relais placentaire. Annls Endocrinol. 33, 221-230.

Clabaut, M. (1973) Délai d'apparition et évolution d'une baisse d'activité des cellules épithéliales et endothéliales après biovariectomie chez la ratte gestante avant le relais placentaire. Annls Endocrinol. 24, $31 \mathrm{l}-319$.

Clabaut, M. (1977) Contribution à l'étude des mécanismes susceptibles d'intervenir dans l'avortement provoqué par la biovariectomie chez la ratte. Thèse de Doctorat Es-Sciences. Rouen, France.

Clabaut, M., Dupont, W., Bourgeois, Ph. \& Lafaye, A. (1977) Influence de la gestation et de la biovariectomie sur l'activité corticosurrénalienne chez la ratte. J. Physiol., Paris 73, 63, Abstr.

Clabaut, M., Acritopoulou-Fourcroy, S., Chartrel, N., Duclos, R., Adjroud, O. \& Collado, H. (1986) Variation of myometrial activities and steroid sexual hormones, following bilateral ovariectomy in the rat at midpregnancy. Proc. 2nd Int. Symp. on the Pregnant Uterus, p. 15, abstr. Hungarian Obstetrical and Gynaecological Society and Debrecen regional Committee of the Hungarian Academy of Science, Debrecen.

Creange, J.E., Schane, H.P., Anzalone, A.J., Gordon, B.A. \& Potts, O. (1978) Interruption of pregnancy in rats by azastene, an inhibitor of ovarian and adrenal steroidogenesis. Fert. Steril. 30, 86 90.

Csapo, A.I. \& Pulkkinen, M. (1978) Indispensability of the human corpus luteum in the maintenance of early pregnancy; lutectomy evidence. Obstet. Gynecol. Survey. 33, $69-81$.

Csapo, A.I. \& Resch, B.A. (1979) Induction of preterm labor in the rat by antiprogesterone. Am. J. Obstet. Gynecol. 134, 823-827.

Csapo, A.I. \& Wiest, W.G. (1969) An examination of the quantitative relationship between progesterone and the maintenance of pregnancy. Endocrinology 35, $735-746$.

Csapo, A.I., Dray, F. \& Erdos, T. (1975) The biological effects of injected antibodies to estradiol-17 $\beta$ and to progesterone in pregnant rats. Endocrinology 97, 603-614.

Csapo, A.I., Resch, B., Csapo, E.F. \& Salau, G. (1979) Effects of antiprogesterone on pregnancy. Am. J. Obstet. Gynecol. 133, 176-183.

Deanesly, R. (1973) Termination of early pregnancy in rats after ovariectomy is due to immediate collapse of the progesterone-dependent decidua. J. Reprod. Fert. 35, $183-186$.

Egg, D., Zambelis, N. \& Loewit, K. (1974) Progesterone in peripheral plasma and tissues during pregnancy in the rat. Exp. Path. 9, 307-310.
Fuchs, A.R. (1978) Hormonal control of myometrial function during pregnancy and parturition. Acta endocr., Copenh., Suppl. 221, 1-69.

Garfield, R.E., Sims, S. \& Daniel, E.E. (1977) Gap junctions: their presence and necessity in myometrium during parturition. Science, N.Y. 198, 958-960.

Garfield, R.E., Rabideau, S., Challis, J.R.G. \& Daniel, E.E. (1978a) Ultrastructural basis for maintenance and termination of pregnancy. Am. J. Obstet. Gynecol. 133, 308-315.

Garfield, R.E., Sims, S.M., Kannan, M.S. \& Daniel, E.E. (1978b) Possible role of gap junctions in activation of myometrium during parturition. Am. J. Physiol. 235 (Cell Physiol. 4), C168-C179.

Golos, T.G., Weyhenmeyer, J.A. \& Sherwood, O.D. (1984) Immunocytochemical localization of relaxin in the ovaries of pregnant rats. Biol. Reprod. 30, $257-261$.

Kuriyama, H. \& Suzuki, H. (1976) Changes in electrical properties of rat myometrium during gestation and following hormonal treatments. J. Physiol., Lond. 260, 315-333.

Lafaye, A. \& Frigot, P. (1978) Influence du véhicule sur la vitesse d'action de la progesterone au niveau de la motilité utérine chez la ratte gestante récemment biovariectomisée. Annls Pharmaceutiques françaises 36, 391-396.

Madjerek, Z., De Visser, J., Van Der Vies, J. \& Overbeek, G.A. (1960) Allylestrenol, a pregnancy maintaining oral gestagen. Acta endocr., Copenh. 35, 8-19.

Marshall, J.M. (1959) Effects of estrogen and progesterone on single uterine muscle fibres in the rat. $J$. Physiol., Lond. 197, 935 942.

Morishige, W.K., Pepe, G.J. \& Rothchild, I. (1973) Serum luteinizing hormone, prolactin and progesterone levels during pregnancy in the rat. Endocrinology 92, $1527-1530$.

Peel, S. \& Bulmer, D. (1974) Effects of ovariectomy on the uterus on the proliferation and differentiation of the uterus of the pregnant rat. J. Anat. 119, $569-578$.

Salvidar, J.T. \& Melton, C.E. (1966) Effects in vivo and in vitro of sex steroids on rat myometrium. $A m . J$. Physiol. 211, 835-843.

Scaramuzzi, R.J., Corker, C.S., Young, G. \& Baird, D.T. (1974) Production of antisera to steroid hormones in sheep. In Steroid Immunoassay, pp. 111-132. Ed. C. G. Pierrepoint. Alpha Omega Alpha, Cardiff.

Talo, A. \& Karki, A.E. (1977) Electrical activity of the uterus during early pregnancy and abortion. Acta physiol. scand. 100, 377-381.

Taylor, M.J., Webb, R., Mitchell, M.D. \& Robinson, J.S. (1982) Effect of progesterone withdrawal in sheep during late pregnancy. $J$. Endocr. 92, 85-93.

Wiest, W.G. (1970) Progesterone and 20 $\alpha$-hydroxypregn4-en-3-one in plasma, ovaries and uteri during pregnancy in the rat. Endocrinology 87, 43-48.

Received 22 May 1987 